\title{
Active Control of Nonlinear Base-Isolated Buildings
}

\author{
By A. H. Barbat, ${ }^{1}$ J. Rodellar, ${ }^{2}$ E. P. Ryan, ${ }^{3}$ and N. Molinares ${ }^{4}$
}

\begin{abstract}
Aвstract: A hybrid seismic control system for building structures is considered, which combines a class of passive nonlinear base isolator with an active control system. The active control forces are applied to the structural base with the objective of reducing its absolute displacements. An adaptive control law is formulated to compute the control forces to assure a form of stable behavior of the system under seismic excitation and in the presence of uncertainties in the characteristics of the building and the base isolator. Numerical simulations are performed to assess the effectiveness of the hybrid control system. The global behavior of the structurebase-isolator system is such that the absolute base displacement is significantly reduced, the price paid being a slight increase of the response of the structure.
\end{abstract}

\section{INTRODUCTION}

The main objective in the seismic design of a structure is to keep its response within limits defined by safety, service, and human comfort conditions. This can be achieved by applying traditional seismic design principles, which assume that earthquakes act upon the structure across its fixed base, to assure partial dissipation of the induced energy. Plastic deformation of certain members can occur and, as a result, the structure is damaged to a certain degree.

This disadvantage can be avoided by using passive control systems such as base isolators or a variety of energy dissipation devices. Base-isolation attempts to uncouple the structure from the seismic ground motion by means of replaceable devices, placed between the building and the foundation, capable of absorbing part of the energy induced by earthquakes. Both elastomeric bearings, which are hysteretic systems, and sliding bearings, which are frictional systems (Kelly 1986; Skinner et al. 1993), are used as seismic isolators. Baseisolation systems can provide, under certain circumstances, a level of performance beyond normal design requirements. The most important disadvantage of such systems is the dependence of their effectiveness on the frequency of the excitation. Moreover, they cannot be applied in the case of tall or heavy structures, because of the size of the dynamic forces involved and the risk of endangering the global stability of the structure.

The seismic behavior of buildings can be improved by incorporating into the structure mechanisms equipped with external actuators capable of producing control forces with the aim of reducing their seismic response. These mechanisms are included in a closed loop governed by a computer and they calculate in real time the control forces to be applied to the structure as a function of the measured structural response. Such active control systems are able to adapt themselves to the frequency characteristics of the seismic action (Soong 1990), but they may require large amounts of energy to govern the actuators.

Another class of structural control systems, referred to as

'Res. Prof., Dept. of Struct. Mech., Tech. Univ. of Catalonia, 08034Barcelona, Spain.

'Prof., Dept. of Appl. Math. III, Tech. Univ. of Catalonia, 08034Barcelona, Spain.

Prof., School of Math. and Sci., Univ. of Bath, Claverton Down, BA27AY. England

${ }^{+}$Grad. Student, Dept. of Struct. Mech., Tech. Univ. of Catalonia, 08034-Barcelona, Spain.

Note. Associate Editor: John Tassoulas. Discussion open until November 1, 1995. To cxtend the closing date one month, a written request must be filed with the ASCE Manager of Journals. The manuscript for this paper was submitted for review and possible publication on November 5. 1993. This paper is part of the Journal of Engineering Mechanics, Vol. 121, No. 6, June, 1995. C)ASCE, ISSN 0733-9399/95/0006-0676$0684 / \$ 2.00+\$ .25$ per page. Paper No. 7304 hybrid systems, has been suggested. They combine different passive and/or active systems with the objective of reducing some of the limitations. One of the hybrid systems with most interesting perspectives for buildings consists of the combination of a base isolation with an active system applying control forces to the base.

The base-isolation component can reduce by itself both the interstory drift and the absolute accelerations of the structure. Thus, the structure tends to behave like a rigid body, the price paid being a significant absolute displacement of the base. The objective of the active control component is to reduce this displacement by means of forces applied on the base. The active component of the system is introduced to complement the base isolation, reacting to the absolute motion, producing a resistance scheme not attainable by purely passive means when the structure is subjected to ground excitation (Inaudi and Kelly 1990). From a practical point of view, this hybrid scheme is appealing since it is possible to achieve the aforementioned objective by means of a single force, which does not exceed some acceptable limits due to the high flexibility of base isolators. From a theoretical point of view, the development of a control law to calculate the active force involves difficulties associated with the nonlinear behavior of the base isolators, with the uncertainties in the models describing the structure-base-isolator system, and in the seismic excitation. A robust control law for linear systems was proposed by Kelley et al. (1987). For linear systems, the application of predictive control was considered (Inaudi et al. 1992), as well as a form of the bang-bang control (Inaudi and Kelly 1991). The nonlinearity of the isolators was considered by Yang et al. (1992), assuming no uncertainties in the structure-base model. Some experimental works with smallscale hybrid systems were also reported (Feng et al. 1993; Riley et al. 1992; Nagarajaiah et al. 1992).

In this paper we present a new active control law for baseisolated structures. In subsequent sections the control problem is stated, a model of the system is described, the control strategy is presented, and some issues concerning its implementation are discussed. Numerical examples are presented to illustrate the effectiveness of the control strategy.

\section{ACTIVE CONTROL PROBLEM}

Consider the building with the hybrid control system illustrated in Fig. 1. The passive component consists of a base isolator, while the active component provides control forces applied on the structural base. We address the problem of designing a feedback control law to generate the active forces. Since the effect of these forces is additional to that of the base isolation, it is important to understand the essential behavior of the structure under purely passive conditions before defining the objective of the active control law.

When the parameters of the isolator are well tuned to the 


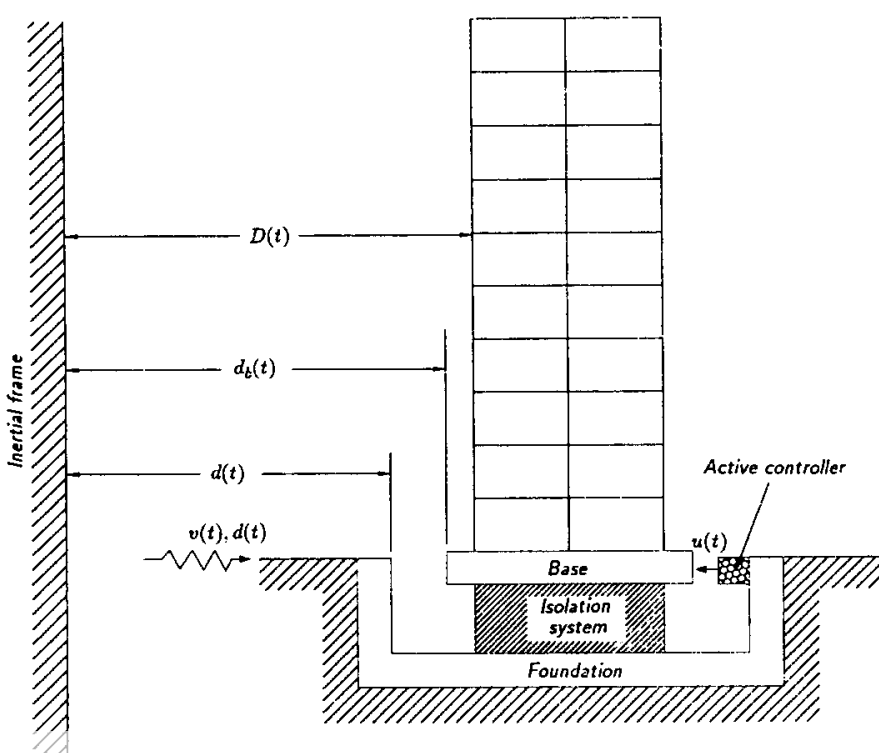

FIG. 1. Building Structure with Hybrid Control System

characteristics of the earthquake, good performance of the structure, with a reduced interstory drift, may be expected. Nevertheless, this desirable interstory behavior can be associated with unacceptably high base displacements. Therefore, the main purpose of the active control forces is to reduce these base displacements. However, since the base and the
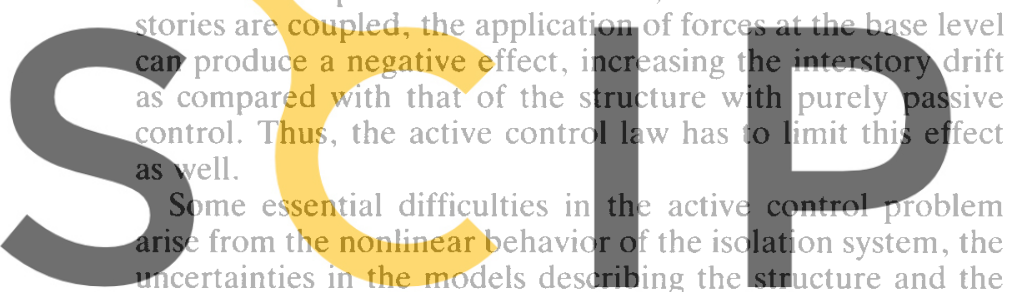

structure and the isolator, and the uncertainties inherent to the seismic actions. These difficulties are magnified by the fact that the overall

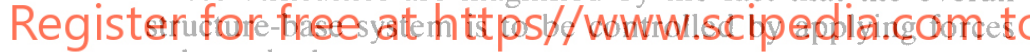
only to the base.

In an earlier paper (Rodellar and Ryan 1993) a control method was proposed for a class of uncertain mechanical systems that can be decomposed into two coupled subsystems, with feedback control on one of them. Under appropriate assumptions, this control assures a form of so-called practical stability. The control law has an adaptive nature that does not require a priori knowledge of either the system parameters or the external excitations. The hybrid structural control problem we are dealing with here can be cast within the framework of this class of systems, the base being the subsystem with control, and the structure the residual subsystem. The objective of the active control law is essentially to drive the displacement and velocity of the base asymptotically to an arbitrarily small neighborhood of the equilibrium position, while keeping the interstory drift within acceptable bounds.

\section{SYSTEM DESCRIPTION}

The structure's dynamic behavior with the hybrid control system can be described by means of a model composed of two coupled systems: $\Sigma_{\text {r }}$ (the building or structure) and $\Sigma_{\text {, }}$ (the base). It is assumed that the structure behaves linearly due to the effect of the base isolation. The behavior of the isolator is assumed to be nonlinear, with hysteretical and/or frictional characteristics. The position of the structure (at time $t)$ is described by a vector $\mathbf{D}(t) \in R^{\prime \prime}$, which represents the horizontal displacements of the $n$ degrees of freedom respect to an inertial frame, while the displacement of the structural base is described by a single degree of freedom with horizontal displacement $d_{b}(t) \in R$ relative to the abovementioned frame. The dynamic excitation is produced by a horizontal seismic ground motion, characterized by an inertial displacement function $t \rightarrow d(t)$ : the function $d(\cdot)$ is assumed to be absolutely continuous on the compact subintervals of $(0, x)$ and so is differentiable almost everywhere (with derivative $\dot{d}=$ $v)$. A single horizontal control force $u(t)$ acts on the structural base. Thus, the equations of motion are

$$
\begin{aligned}
& \sum_{r}: \mathbf{M} \ddot{\mathbf{D}}+\mathbf{C} \dot{\mathbf{D}}+\mathbf{K D}=\mathbf{C} \mathbf{J} \dot{d}_{b}+\mathbf{K} \mathbf{J} d_{b} ; \\
& \mathbf{D}(0)=\mathbf{D}^{\prime \prime} \in R^{n}, \dot{\mathbf{D}}(0)=\mathbf{V}^{0} \in R^{n} \\
& \sum_{c}: m_{b} \ddot{d}_{b}+\left[c_{b}+\mathbf{J}^{T} \mathbf{C} \mathbf{J}\right] \dot{d}_{b}+\left[k_{b}+J^{T} \mathbf{K} \mathbf{J}\right] d_{b} \\
& -\mathbf{J}^{T} \mathbf{C} \dot{\mathbf{D}}-\mathbf{J}^{T} \mathbf{K} \mathbf{D}-c_{b},-k_{b}, d+f\left(d_{b}, \dot{d}_{b}, d, \imath\right)=u ; \\
& d_{b}(0)=d_{b}^{\prime \prime} \in R, \dot{d}_{b}(0)=v_{b}^{\prime \prime} \in R
\end{aligned}
$$

where $\mathbf{M}, \mathbf{C}$, and $\mathbf{K}=$ mass, damping, and stiffness matrices of the structure, respectively, each of dimension $n \times n$. The vector $\mathbf{J}=$ rigid body motion according to the degrees of freedom of the model (in this case it is the unit vector $J=$

$[1,1, \ldots, 1,1])$; and scalars $m_{b}, c x_{b}$, and $k_{b}=$ mass, damping, and stiffness of the base. The last two parameters correspond to the elastic and damping forces that appear on the base due to the linear effects of the isolator; $f$ is an additional horizontal force produced on the structural base by nonlinearities in the isolator

Before formulating the control law, the description of the

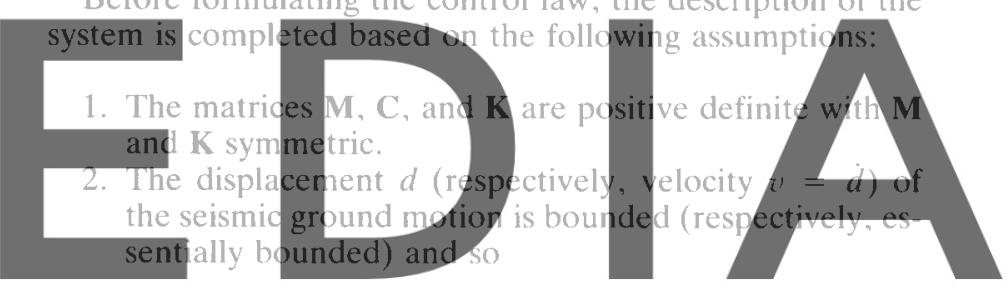

$$
\left|c_{b}, r(t)+k_{b} d(t)\right| \leq \nu
$$

\section{dowrfoeldothed velosion wittroutsthe watermark function $\gamma$, is such that, for some known continuous function $\gamma^{\prime}$, the following holds for some (unknown) scalar $\alpha$}

$$
\left|f\left(d_{b}, \nu_{b}, d(t) \tau^{\prime}(t)\right)\right| \leq \alpha^{\prime} \gamma^{\prime}\left(d_{b}, \tau_{b}\right)
$$

for almost all $t$ and all $d_{b}$ and $v_{b}$.

Remarks: Assumption 1 ensures that the equilibrium $\{0\}$ of the unforced system $\ddot{\mathbf{M D}}+\mathbf{C \dot { D }}+\mathbf{K D}=0$ is (globally) asymptotically stable. Assumption 3 is weak. For example, if it is known only that $f$ depends polynomially (of any degree) on its first two arguments, then 3 holds with $\gamma^{\prime}\left(d_{b}, z_{b}\right)=$ $\exp \left(\sqrt{d_{h}^{2}+y_{h}^{2}}\right)$

\section{CONTROL STRATEGY}

Fix $\eta>0, \lambda>0$ and $\bar{k}>0$ (design parameters). Write

$$
p_{l}(t)=\eta d_{l}(t)+\dot{d}_{l}(t)
$$

and define

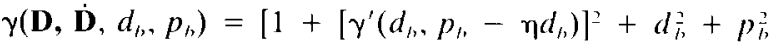

$$
\begin{aligned}
& \left.+\|\mathbf{D}\|^{2}+\|\dot{\mathbf{D}}\|^{2}\right]^{1 / 2}
\end{aligned}
$$

The proposed control strategy is

$$
\begin{aligned}
& u(t)=-k(t)\left[p_{l}(t)+\gamma\left(\mathbf{D}(t), \dot{\mathbf{D}}(t), d_{t,}(t), p_{t,}(t)\right) s_{\lambda}\left(p_{t,}(t)\right)\right] \\
& \dot{k}(t)=\bar{k}|| p_{b}(t)\left|+\gamma\left(\mathbf{D}(t), \dot{\mathbf{D}}(t), d_{t,}(t), p_{t,}(t)\right)\right| \rho_{\lambda}\left(p_{t}(t)\right)
\end{aligned}
$$




$$
k(0)=k^{0} \text { (initial condition) }
$$

where the continuous functions $s_{\lambda}, \rho_{\lambda}$ are given by

$$
\begin{gathered}
s_{\wedge}\left(p_{b}\right)= \begin{cases}\left|p_{b}\right|^{-1} p_{b}, & \text { if }\left|p_{b}\right| \geq \lambda \\
\lambda{ }^{\prime} p_{b}, & \text { if }\left|p_{b}\right|<\lambda\end{cases} \\
\rho_{\lambda}\left(p_{b}\right)= \begin{cases}\left|p_{b}\right|-\lambda, & \text { if }\left|p_{b}\right| \geq \lambda \\
0, & \text { if }\left|p_{b}\right|<\lambda\end{cases}
\end{gathered}
$$

The rationale for this control strategy lies in its capacity to ensure a form of practical stability, as we show in the next section. The intuition underpinning the strategy is as follows. If the (continuous) saturation function $s_{\lambda}$ is replaced by the (discontinuous) signum function sgn, then, for sufficiently large $\bar{k}$, the control

$$
u=-\bar{k}\left[p_{b},+\lambda\left(\mathbf{D}, \dot{\mathbf{D}}, d_{b}, p_{b}\right) \operatorname{sgn}\left(p_{b}\right)\right]
$$

ensures that the subspace $\left\{\left(\mathbf{D}, \dot{\mathbf{D}}, d_{b}, p_{b}\right) \in R^{2(n+1)} \mid p_{b}=0\right\}$ is attained in finite time, and the motion is subsequently constrained thereon: by the differential equation $\dot{d}_{b}=-\eta d_{b}+$ $p_{b}$, we conclude that $d_{b}(t)$ tends exponentially to zero, with the decay rate determined by the parameter $\eta$. By the differential equation defining subsystem $\Sigma_{r}$ and its stability in the absence of force (by assumption 1), it follows that $\mathbf{D}(t)$ and $\dot{\mathbf{D}}(t)$ are also asymptotic to zero, from which the stability of the overall system results. Thus, the discontinuous strategy with fixed gain $k$ is closely akin to concepts in variable structure control [see, for example, Utkin (1978)]. Here, we cir-

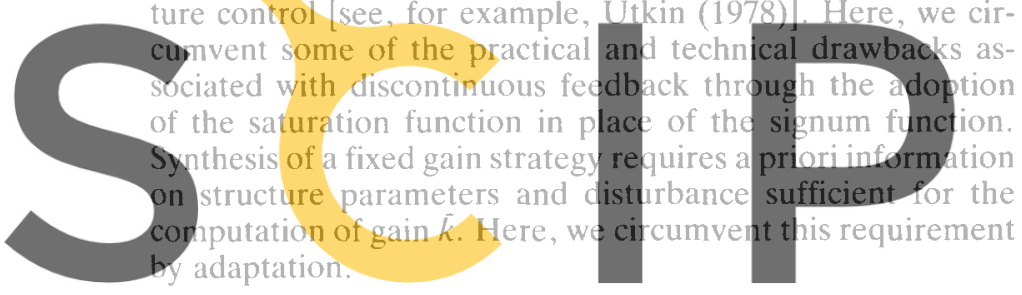

STABILITY ANALYSIS

Register for free at https//WwW. Scipedia. com to $2 n+3$, now becomes

$$
\begin{aligned}
& \mathbf{M} \ddot{\mathbf{D}}(t)+\mathbf{C D}(t)+\mathbf{K D}(t)=\mathbf{C J}\left[p_{b}(t)-\eta d_{b}(t)\right]+\mathbf{K} \mathbf{J} d_{b}(t) \\
& \dot{d}_{b}(t)=-\eta d_{b}(t)+p_{b}(t) \\
& \dot{p}_{b}(t)=P_{\lambda}\left(t, \mathbf{D}(t), \dot{\mathbf{D}}(t), d_{b}(t), p_{b}(t), k(t)\right) \\
& \left.\dot{k}(t)=\bar{k} \| p_{b}(t) \mid+\gamma\left(\mathbf{D}(t), \dot{\mathbf{D}}(t), d_{b}(t), p_{b}(t)\right)\right] \rho_{\lambda}\left(p_{b}(t)\right) \\
& \left(\mathbf{D}(0), \dot{\mathbf{D}}(0), d_{b}(0), p_{b}(0), k(0)\right)=\left(\mathbf{D}^{0}, \mathbf{V}^{0}, d_{b}^{0}, p_{b}^{0}, k^{0}\right) \\
& =: \xi^{\prime \prime} \in R^{N}
\end{aligned}
$$

where the function $P_{\curlywedge}$ is given by

$$
\begin{aligned}
& P_{\mathrm{\Lambda}}\left(t, \mathbf{D}, \dot{\mathbf{D}}, d_{b}, p_{b}, k\right):=-\eta^{2} d_{b}+\eta p_{b} \\
& \quad+m_{b}{ }^{\prime}\left[g\left(t, \mathbf{D}, \dot{\mathbf{D}}, d_{b}, p_{b}\right)\right. \\
& \left.\quad-k\left[p_{h}+\gamma\left(\mathbf{D}, \dot{\mathbf{D}}, d_{b}, p_{b}\right) s_{\lambda}\left(p_{b}\right)\right]\right]
\end{aligned}
$$

with

$$
\begin{aligned}
& g\left(t, \mathbf{D}, \dot{\mathbf{D}}, d_{b}, p_{b}\right):=\mathbf{J}^{T}[\mathbf{C D}+\mathbf{K} \mathbf{D}] \\
& \quad+c_{b},(t)+k_{b} d(t)-f\left(d_{b}, p_{b}-\eta d_{b}, d(t), v(t)\right) \\
& \quad-\left[c_{b}+\mathbf{J}^{T} \mathbf{C J}\right]\left[p_{b}-\eta d_{b}\right]-\left[k_{b}+\mathbf{J}^{T} \mathbf{K J}\right] d_{b}
\end{aligned}
$$

Observe that, for almost all $t$ and all $\mathbf{D}, \mathbf{D}, d_{b}, p_{b}$

$$
\left|g\left(t, \mathbf{D}, \dot{\mathbf{D}}, d_{b}, p_{b}\right)\right| \leq \alpha \gamma\left(\mathbf{D}, \dot{\mathbf{D}}, d_{b}, p_{b}\right)
$$

for some (unknown) constant $\alpha>0$.

Writing $\xi(t)=\left(\mathbf{D}(t), \dot{\mathbf{D}}(t), d_{b}(t), p_{b}(t), k(t)\right)$, system (8) may be expressed as

$$
\dot{\xi}(t)=F_{\lambda}(t, \xi(t)), \xi(0)=\xi^{0}
$$

where

$$
\begin{aligned}
& F_{\lambda}(\xi):=\left(\dot{\mathbf{D}}, \mathbf{M}^{-1}\left[-\mathbf{C} \dot{\mathbf{D}}-\mathbf{K D}+\mathbf{C} \mathbf{J}\left[p_{h}-\eta d_{h}\right]\right.\right. \\
& \left.\left.\quad+\mathbf{K} \mathbf{J} d_{b}\right], p_{b}-\eta d_{b}, p_{\lambda}(t, \xi), K_{\lambda}(\xi)\right)
\end{aligned}
$$

with

$$
K_{\lambda}(\xi):=\bar{k}\left[\left|p_{b}\right|+\gamma\left(\mathbf{D}, \dot{\mathbf{D}}, d_{b}, p_{b}\right)\right] \rho_{\lambda}\left(p_{b}\right)
$$

This system satisfies the classical Carathéodory conditions and so, for every $\xi^{0} \in R^{N}$, the initial-value problem has a solution and every solution can be extended into a maximal solution (Coddington and Levinson 1953).

Theorem: Let $\lambda>0$ and $\xi^{0} \in R^{N}$. For every maximal solution

$$
\xi(\cdot)=\left(\mathbf{D}, \dot{\mathbb{D}}, d_{h,} p_{h}, k\right)(\cdot):[0, \omega] \rightarrow R^{N}
$$

of the initial-value problem (9) [equivalently (8)]: (1) $\omega=$

$\infty$; (2) $\lim _{t \rightarrow \infty} k(t)$ exists and is finite; (3) $\rho_{\lambda \eta}, 1\left(d_{l},(t)\right)$ and $\rho_{\lambda}\left(p_{b}(t)\right) \rightarrow 0$ as $t \rightarrow \infty ;(4)$ for some positive scalar $c$, $\rho_{c \lambda}\left(\sqrt{\|\mathbf{D}(t)\|^{2}+\|\mathbf{D}(t)\|^{2}}\right) \rightarrow 0$ as $t \rightarrow \infty$. Proof: See Appendix I. Remarks: The preceding result may be paraphrased as follows: (1) Forward-time solutions are globally defined; (2) the monotone gain function does not grow unbounded; (3) the state of the base, characterized by the coordinates $\left(d_{h}\right.$,

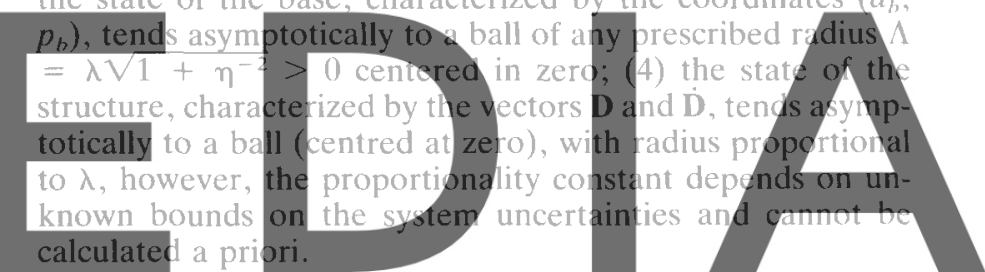

It is important to emphasize the paucity of knowledge on the system that is required a priori. From the control law, it

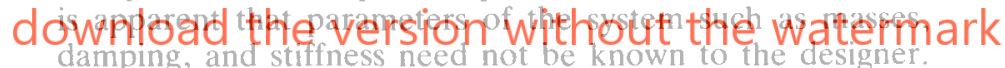
The external seismic excitation is unknown, assuming only that it is bounded by an unknown constant, as in (2). Regarding the nonlinear force $f$ produced by the isolators, the control strategy allows it to be unknown but bounded, modulo arbitrary scaling, by a known continuous function as in (3). This function enters into the control law in the definition of the function $\gamma$ in (5). The adaptive nature of the control law, associated with the time-varying gain $k(t)$, guarantees the stability properties for any realization of the unknown parameters satisfying assumptions $1-3$.

For the implementation of the control law, the absolute displacement and velocity responses of the base and the structure are required as feedback information. With this information, (6) and (7) are used to calculate the value of the control $u(t)$. The parameters (positive-valued) $\eta, \lambda, k_{0}$, and $\hat{k}$ are open to choice by the designer. $\Lambda=\lambda \sqrt{1+\eta^{-2}}$ is the most significant quantity. It defines the guaranteed stability ball and has a primary influence on achieving the control objective.

\section{NUMERICAL EXAMPLES}

To assess the effectiveness of the aforementioned control law, numerical simulations are presented for two types of base-isolated structures. In the first example, the structure is modeled as a single-degree-of-freedom system. The second example considers a 10 -story shear building.

For the force $f$, we need to specify the model describing 


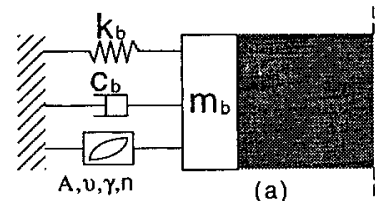

(a)

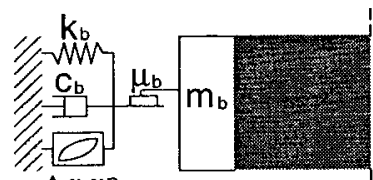

(b)

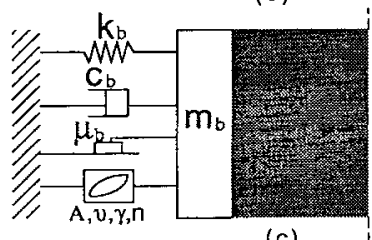

(c)

FIG. 2. Base-Isolation Systems: (a) New Zealand (NZ); (b) NZ with Frictional System Connected in Series (AIZ + F-SCR); (c) AI with Frictional System Connected in Parallel (NZ + F-PAR)

the nonlinear behavior of the isolating devices. Two types of behavior are considered, one frictional and the other hysteretical. In Fig. 2, three isolators are defined for different combinations of the two types of behavior. These are the New Zealand (NZ) isolator [Fig. 2(a)] (Su et al. 1989), characterized by a purely hysteretical performance, the NZ with a purely frictional system connected in series (NZ + F-SER) [Fig. 2(b)], and the NZ with a purely frictional system con-

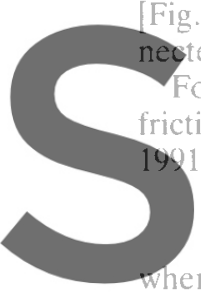

in parallel (NZ + F-PAR)

For frictional isolation devices,

actional force $f_{1}$ was proposed by Nagarajai

1) by an equation

$f_{1}=-\operatorname{sgn}(x)\left[\mu_{m}\right.$

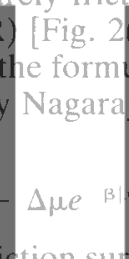

(c)].

tion of a purely

here $O=$ force normal to the friction sufface; $\mu=$ friction coefficient; $\beta=$ a constant; $\mu_{\max }=$ coefficient for high sliding velocity; $\Delta \mu=$ difference between $\mu_{\max }$ and the friction coef-

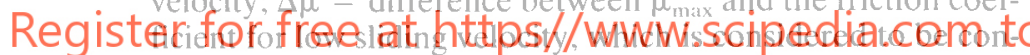
stant; and $x=$ displacement of the base relative to the ground, e. $x=d_{1}-d$

One way to formulate a hysteretical isolation device is to use constitutive models defined by differential equations. In this paper, with the purpose of illustrating the application of the proposed control law, Wen's (1976) uniaxial model is adopted. The hysteretic force $f_{2}$ is expressed by the following equation:

$$
f_{2}=f^{y} z
$$

where $f y=$ yielding force; and $z=$ an auxiliary variable defined by the differential equation

$$
\frac{d z}{d x}=A \pm\left(v_{1} \pm v_{2}\right) z^{m}
$$

The parameters $A, v_{1}, v_{2}$, and $m$ allow the description of the hysteretical cycles for a wide class of materials, ranging from elastic to elastoplastic materials (Wen 1976).

To implement the control law, the force $f$ is required to be bounded in the form expressed in (3). In the cases we consider here, $f$ is a combination (as illustrated in Fig. 2) of forces of types defined by $(8)-(10)$. Therefore, we consider that the force $f$ is bounded by a constant. This implies that the function $\gamma^{\prime}$ in (3), also appearing in the control law in (5), is just equal to 1. It simplifies the implementation of the control law and, as ultimately verified through the numerical simulations, gives satisfactory results.

\section{Example 1}

The purpose of this example is to analyze the effectiveness of the three hybrid control systems with the proposed control law for a frequency range covering a wide class of building structures. This effectiveness is compared with that of the corresponding purely passive systems. To do this, a singledegree-of-freedom model with a mass of $6 \times 10^{5} \mathrm{~kg}$ is considered. Its stiffness is varied in such a way that the natural period lies in the range between $0.1 \mathrm{~s}$ and $1.0 \mathrm{~s}$. The mass of the base is also $6 \times 10^{5} \mathrm{~kg}$, and its stiffness is $1.184 \times 10^{7}$ $\mathrm{N} / \mathrm{m}$. The characteristics of the frictional bearings are: $\mu=$
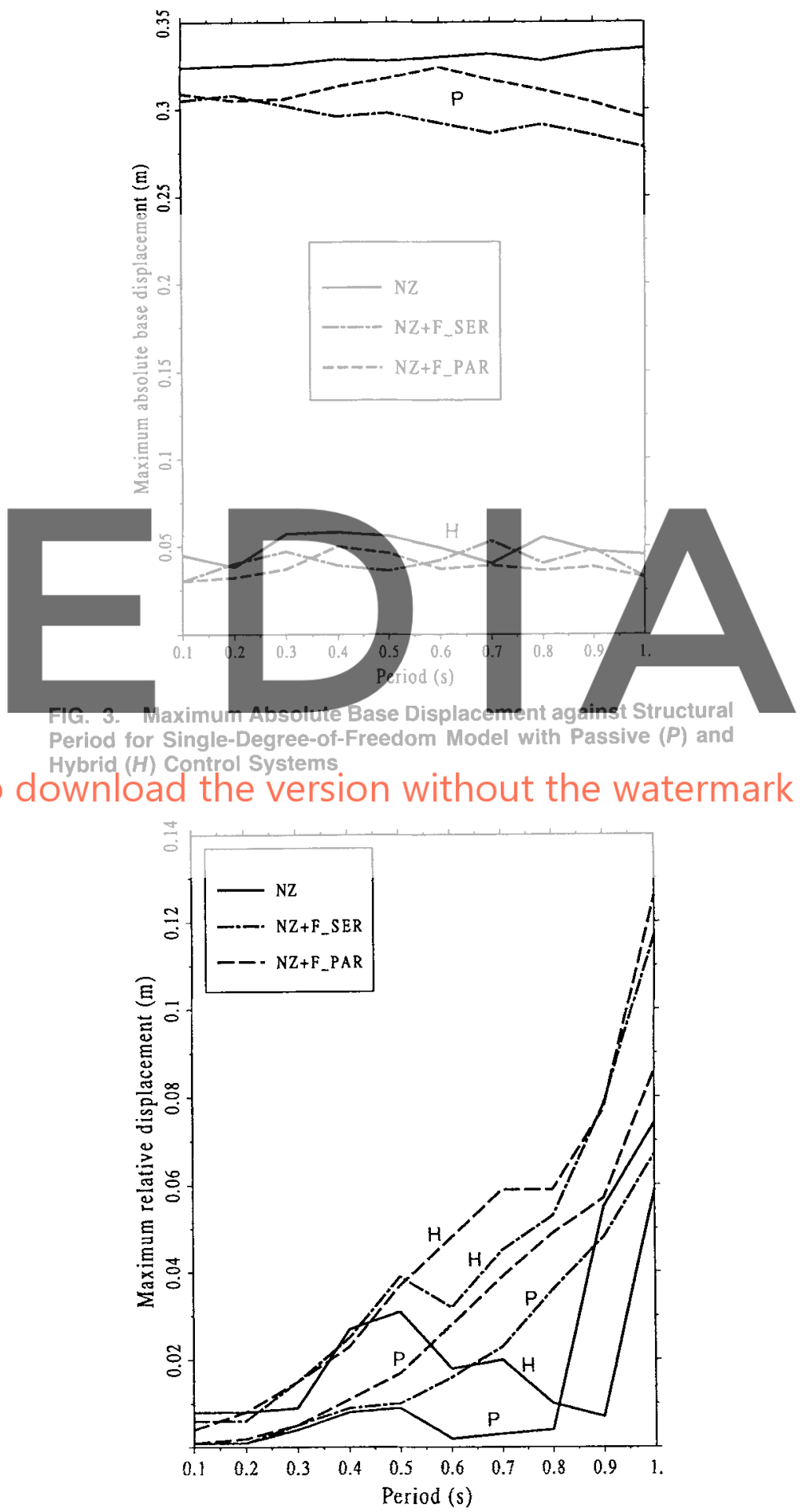

FIG. 4. Maximum Relative Displacement against Structural Period for Single-Degree-of-Freedom Model with Passive $(P)$ and $\mathrm{Hy}$ brid $(H)$ Control Systems

JOURNAL OF ENGINEERING MECHANICS / JUNE 1995 / 679 


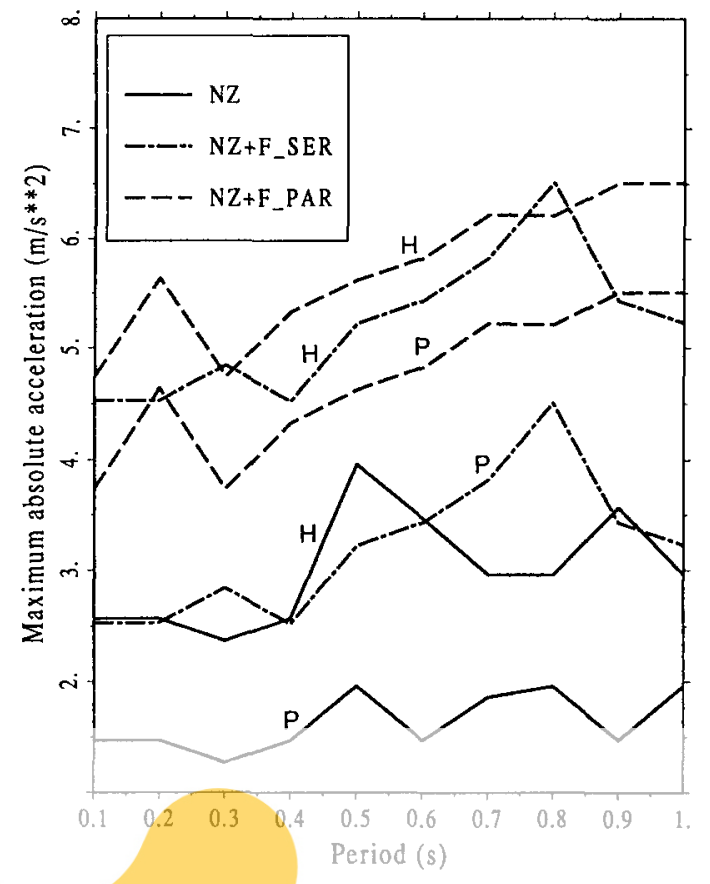

FIG. 5. Maximum Absolute Acceleration against Structural Period for Single-Degree-of-Freedom Model with Passive $(P)$ and Hybrid (H) Control Systems

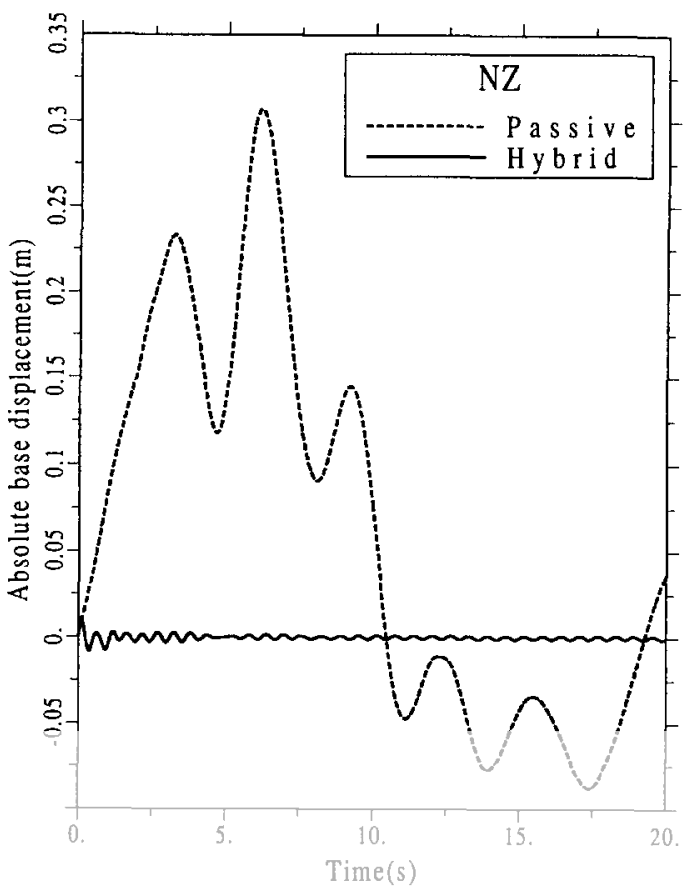

FIG. 7. Absolute Base Displacement of 10-Degrees-of-Freedom Model
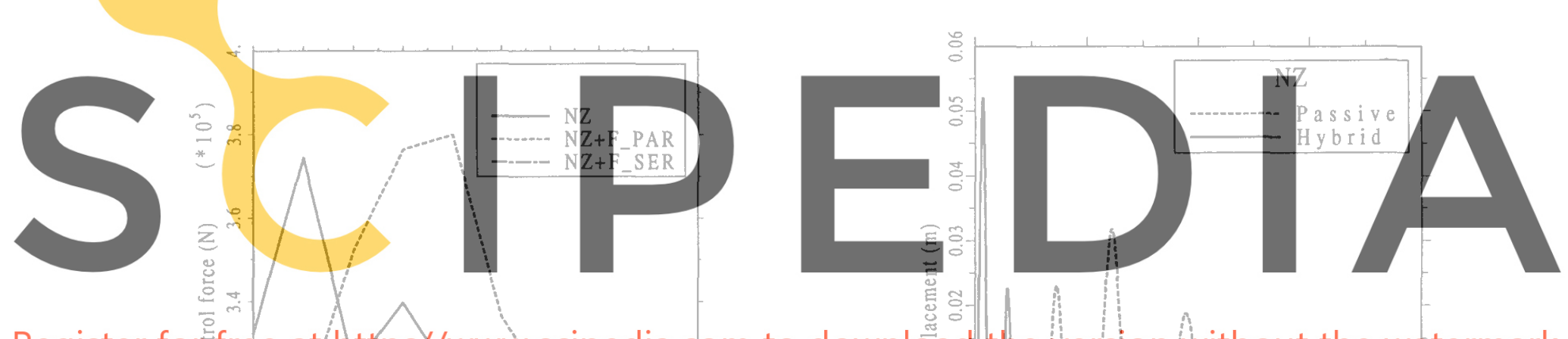

Register for

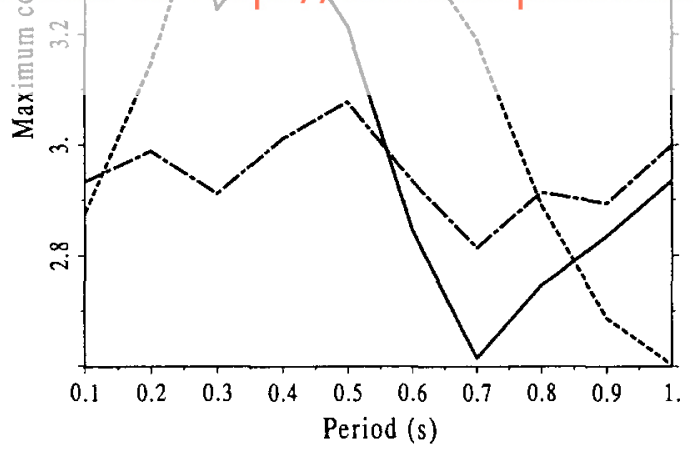

FIG. 6. Maximum Control Force against Structural Period for Single-Degree-of-Freedom Model with Hybrid Control Systems

$0.1, \mu_{\operatorname{mix}}=0.185, \Delta \mu=0.09, \beta=2.0$. For the hysteretic bearings, the following parameters are used: $f^{x}=1.5 \times 10^{3}$ $\mathrm{N}, A=1.0, v_{1}=v_{2}=0.5$, and $m=1$.

The model is subjected to the $1940 \mathrm{El}$ Centro earthquake. For each natural period considered in the analysis, the structural response is simulated solving the equations of motion (1) by a Newmark integration method, and (10) by RungeKutta scheme of the fourth order. This simulation is performed for the three isolators under purely passive conditions (active control is disconnected) and for the hybrid case (active control is operating). The parameters associated with the con- 


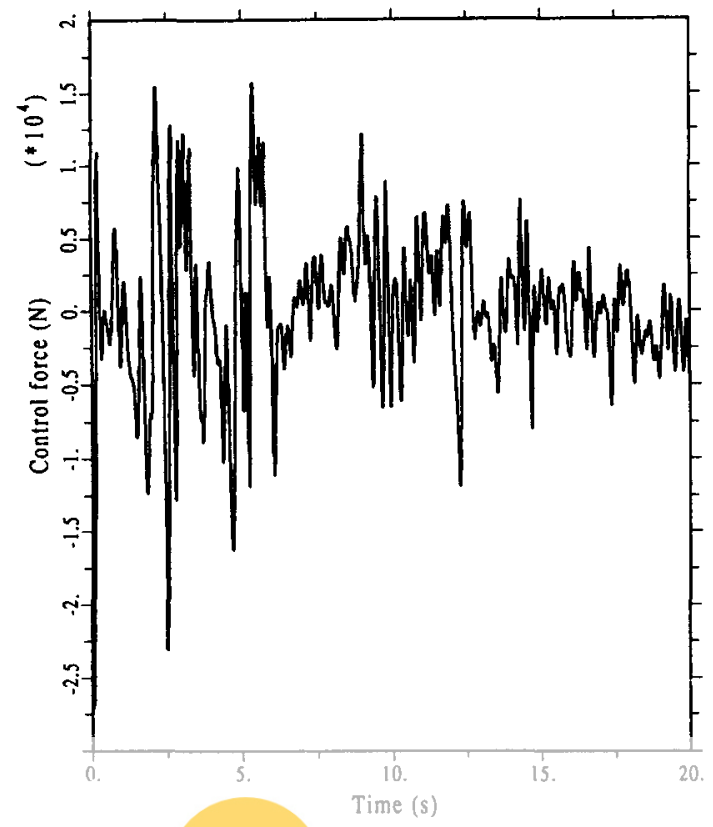

FIG. 9. Active Control Force for 10-Degrees-of-Freedom Model

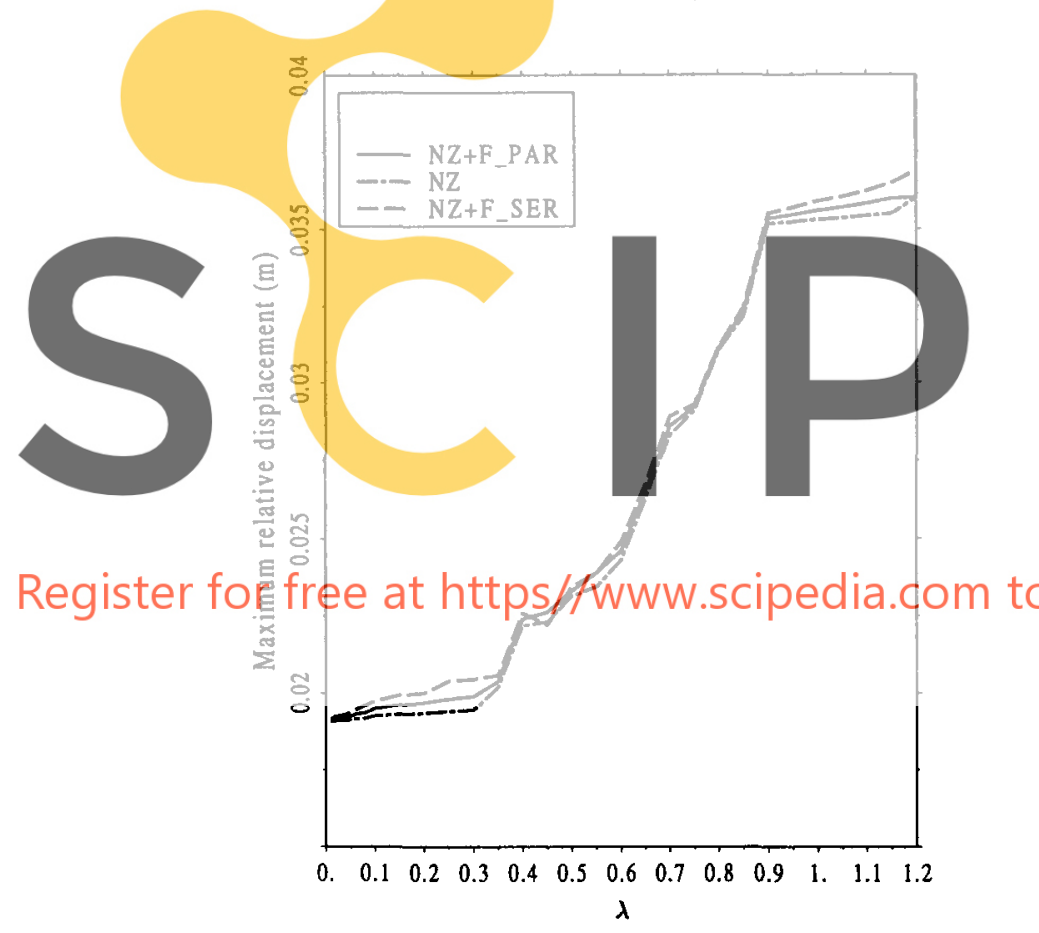

FIG. 10. Maximum Top Floor Relative Displacement for 10-Degrees-of-Freedom Model for Different Values of $\lambda$

value of the control force is plotted against the period for the three isolators, showing an acceptable magnitude.

\section{Example 2}

To assess the behavior of the hybrid system in a more demanding situation, consider a 10 -story building structure as illustrated in Fig. 1. The mass of each level, including that of the base, is $6 \times 10^{5} \mathrm{~kg}$. The stiffness varies in $5 \times 10^{7}$ $\mathrm{N} / \mathrm{m}$ between levels, from $9 \times 10^{8} \mathrm{~N} / \mathrm{m}$ at the first level to $4.5 \times 10^{8} \mathrm{~N} / \mathrm{m}$ at the top level. The damping ratio is 0.05 . The characteristics of the base-isolation devices are the same as those in the single-degree-of-freedom case.

The control law has been applied to the New Zealand base isolator and the $1940 \mathrm{El}$ Centro earthquake, considered as

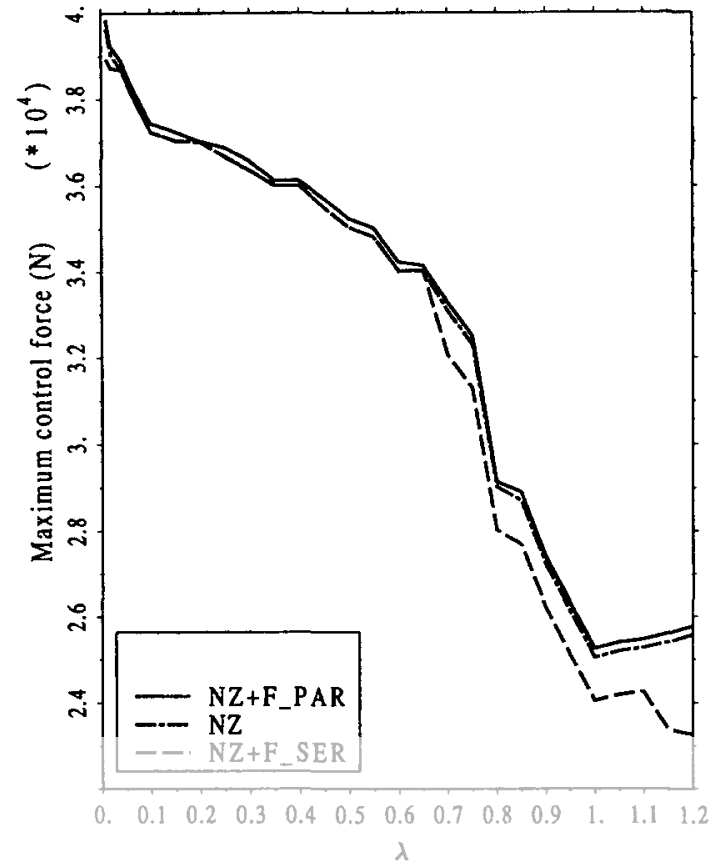

FIG. 11. Maximum Control Force for 10-Degrees-of-Freedom Model for Different Values of $\lambda$

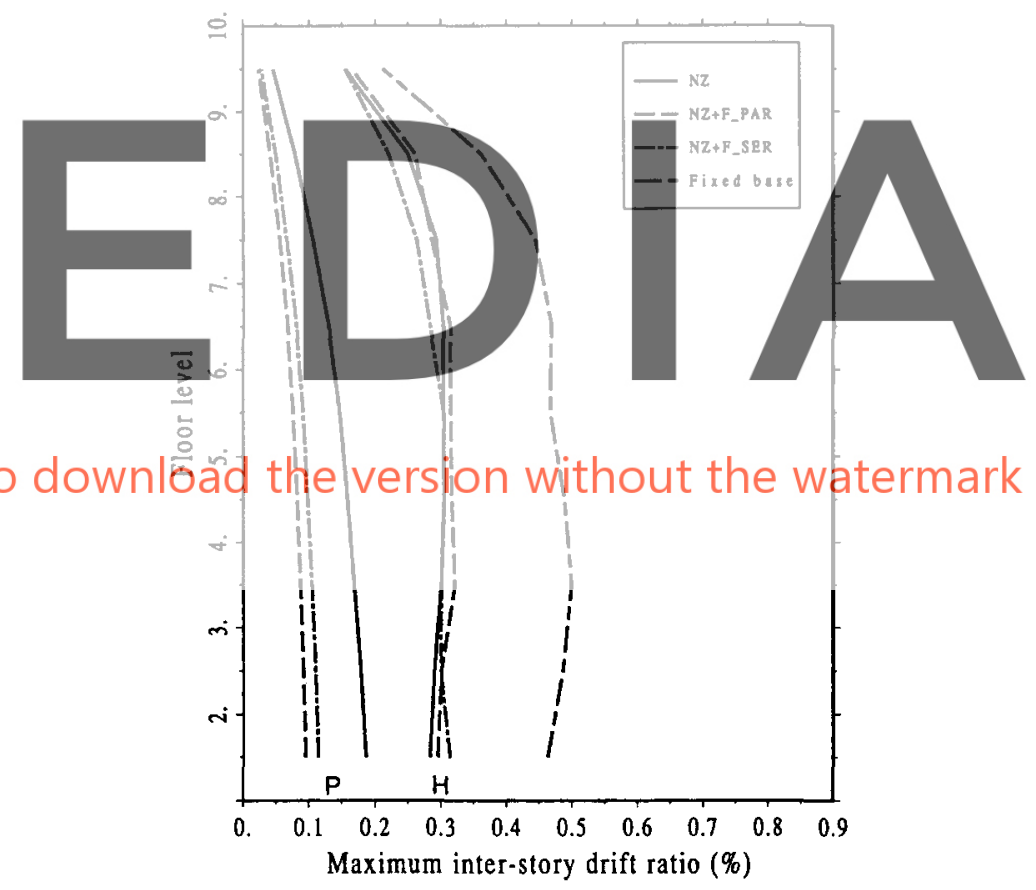

FIG. 12. Variation of Maximum Interstory Drift Ratio with Floor Level

excitation. Figs. 7 and 8 show the time histories of the absolute base displacement and the displacement of the top floor relative to the base for the passive and hybrid cases. Fig. 9 shows the corresponding control force for the hybrid case. In these three figures the parameter $\lambda$ is equal to 0.9. Fig. 7 shows that the absolute base displacement in the hybrid case rapidly enters into a neighborhood around zero, with a response level much lower than the corresponding response to the passive case. Fig. 8 shows that there is an initial period in which the hybrid relative displacement of the top floor is higher than the passive one, but it reduces more rapidly than in the passive case to a neighborhood centered at zero. The behaviors observed in Figs. 7 and 8 fulfill the theoretical objective of the 


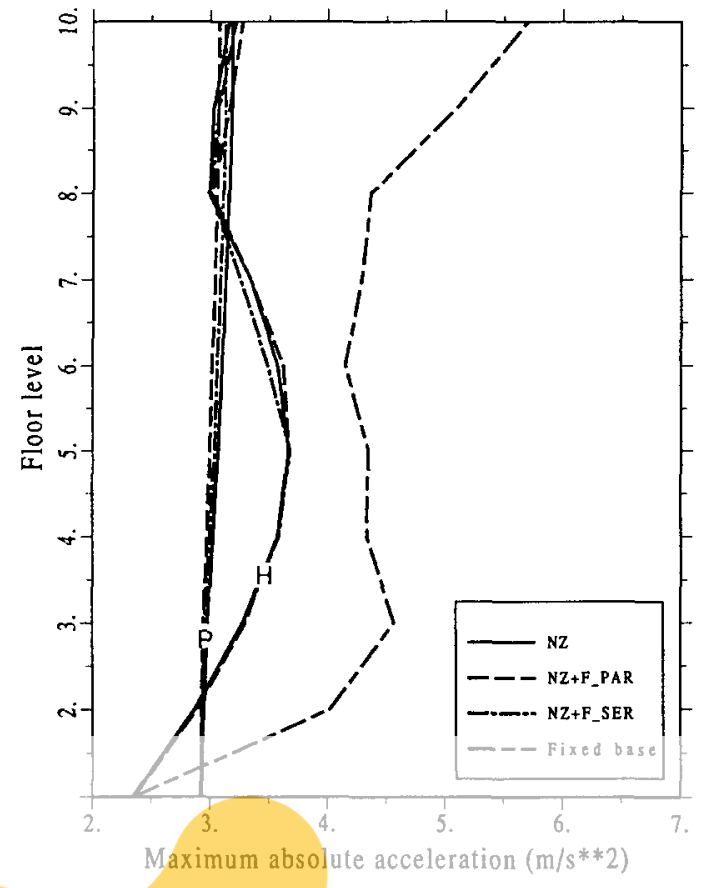

FIG. 13. Variation of Maximum Absolute Acceleration with Floor Level

control law. Fig. 9 shows that the corresponding control force is reasonable.

As mentioned before, $\lambda$ is the most important parameter in the control law, because it defines the size of the geighborhood to which the controlled proach. To evaluate its influence. maximum values of the relative

the control force for different me relative displacement . This is as expected, bease of $\lambda$ implies a less demanding control.

For a more detailed insight on the structural behavior, it

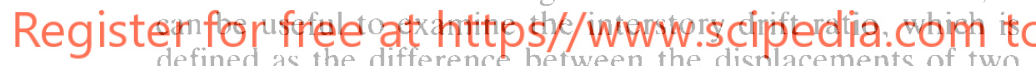
adjacent floors divided by the floor height. Fig. 12 describes the variation of the maximum interstory drift ratio with the floor level for the three base isolators in the purely passive and hybrid cases. For comparison purpose, the same is shown for the structure with the fixed base. An increase of the maximum values for the hybrid cases is observed as compared with the passive cases. A similar pattern can be seen in Fig. 13, in which the maximum floor accelerations are plotted for the same cases. Nevertheless, when considering both the structure and the base, an improvement in the global behavior can be recognized.

\section{CONCLUSIONS}

The hybrid control system discussed in this paper combines a nonlinear base-isolation component with an active one applying forces at the base level. The main purpose was to propose a new feedback control law for the active component, and to explore its potential through simulation examples.

The objective for the control law was posed in terms of stability, and two very important features present in hybrid systems have been taken into account: (1) uncertainties in knowledge on the structure, the isolators, and the excitation; and (2) the nonlinear behavior of the isolator devices. Regarding the uncertainties, knowledge of the parameters of the base and structure model are not required in the control law, because of its adaptive nature. Concerning the nonlinearities in the isolator, for illustrative purposes, a variety of hysteretic and frictional characteristics were considered in the examples.

In the evaluation of the structural behavior, the following variables were checked: the absolute base displacement, the interstory drift, and the absolute acceleration of the structure. The numerical results show that the active control force significantly reduces the base displacement of the structure, producing a slight increase in the structural response, with respect to the purely passive case. However, the global structural behavior improves when the hybrid system is used. This can be particularly significant to excitations with predominant frequencies in the range in which the purely passive base-isolated structure has its maximum response.

The emphasis of this paper was on the adaptive control law, with the examples illustrating its features. The results presented show a clear potential for this control law. Its capabilities need to be more extensively assessed by means of a systematic numerical application in a variety of operating conditions: different structural models, isolator nonlinearities, seismic excitations, etc., completed with experimental verification.

\section{APPENDIX I. PROOF OF THEOREM}

\section{Let $V$ be the $C^{1}$ function $R \rightarrow[0, x)$ given by}

$$
V\left(p_{b}\right):=\frac{1}{2} \rho_{\lambda}^{2}\left(p_{n}\right)
$$

For almost all $t \in R$ and all $\xi=\left(\mathbb{D}, \mathbf{D}, d_{b}, p_{b}, k\right) \in R^{N}$.

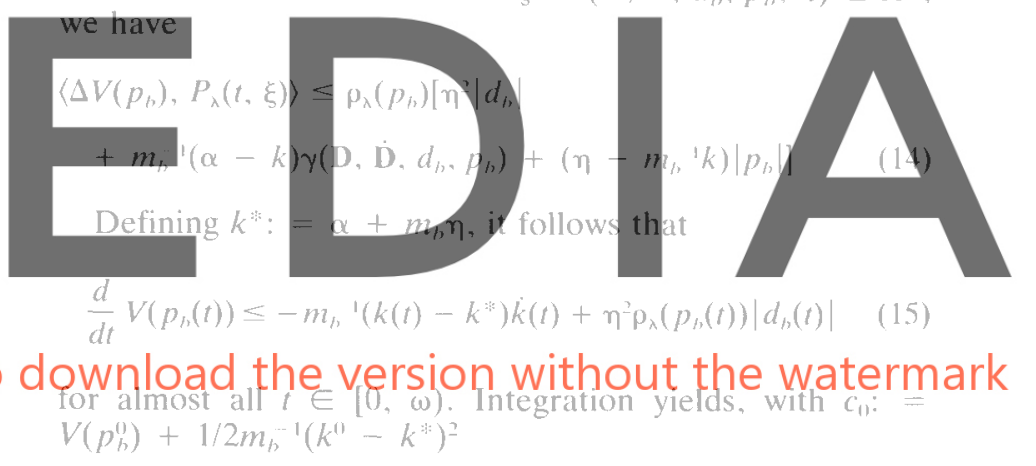

$$
\begin{aligned}
0 & \leq V\left(p_{c}(t)\right) \leq c_{0}-\frac{1}{2} m_{l^{\prime}}\left(\left(k(t)-k^{*}\right)^{2}\right. \\
& +\eta^{2} \int_{11}^{t} \rho_{\lambda}\left(p_{b}(s)\right)\left|d_{t}(s)\right| d s
\end{aligned}
$$

which is valid for all $t \in[0, \omega)$.

We briefly digress to prove a technicality. Proposition: For some positive scalar $c_{1}$

$$
\int_{0}^{l} \rho_{\lambda}\left(p_{b}(s)\right)\left|d_{b}(s)\right| d s \leq c_{1} \int_{11}^{l}\left|\rho_{\lambda}\left(p_{b}(s)\right)+\rho_{\lambda}^{2}\left(p_{h}(s)\right)\right| d s
$$

for all $t \in[0, \omega)$. Proof: First observe that by the differential equation $\dot{d}_{h}=-\eta d_{b}+p_{h}$

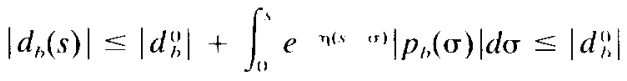

$$
\begin{aligned}
& \left.+\int_{0}^{s} e^{\eta(s} \omega\right)\left[p_{\lambda}\left(p_{b}(\sigma)\right)+\lambda\right] d \sigma \leq\left|d_{b}^{\prime \prime}\right|+\lambda \eta \quad \\
& +\int_{0}^{s} e^{\eta(s . s)}{ }^{s)} \rho_{\lambda}\left(p_{h}(\sigma)\right) d \sigma
\end{aligned}
$$

Therefore 


$$
\begin{aligned}
& \int_{0}^{t} \rho_{\lambda}\left(p_{b}(s)\right)\left|d_{b}(s)\right| d s \leq\left(\left|d_{b}^{0}\right|+\lambda \eta^{-1}\right) \int_{0}^{t} \rho_{\lambda}\left(p_{b}(s)\right) d s \\
& \quad+\int_{0}^{1} \rho_{\lambda}\left(p_{b}(s)\right) \int_{0}^{s} e^{-\eta(s-\sigma)} \rho_{\lambda}\left(p_{b}(\sigma)\right) d \sigma d s
\end{aligned}
$$

Applying Hölder's inequality to the second term on the right

$$
\begin{gathered}
\int_{0}^{t} \rho_{\lambda}\left(p_{b}(s)\right) \int_{0}^{s} e^{-\eta(s-\sigma)} \rho_{\lambda}\left(p_{b}(\sigma)\right) d \sigma d s \leq\left(\int_{0}^{t} \rho_{\lambda}^{2}\left(p_{b}(s)\right) d s\right)^{1 / 2} \\
\cdot\left(\int_{0}^{t} e^{-2 \eta s}\left(\int_{0}^{s} e^{\eta \sigma} p_{\lambda}\left(p_{b}(\sigma)\right) d \sigma\right)^{2} d s\right)^{1 / 2}
\end{gathered}
$$

Integrating by parts in the last term on the right

$$
\begin{aligned}
& \int_{0}^{t} e^{-2 \eta s}\left(\int_{0}^{s} e^{\eta \omega} \rho_{\lambda}\left(p_{b}(\sigma)\right) d \sigma\right)^{2} d s \\
& \quad \leq \eta^{-1} \int_{0}^{t} \rho_{\lambda}\left(p_{b}(s)\right) \int_{0}^{s} e^{-\eta(s \cdots \sigma)} \rho_{\lambda}\left(p_{b}(\sigma)\right) d \sigma d s
\end{aligned}
$$

We may now conclude that

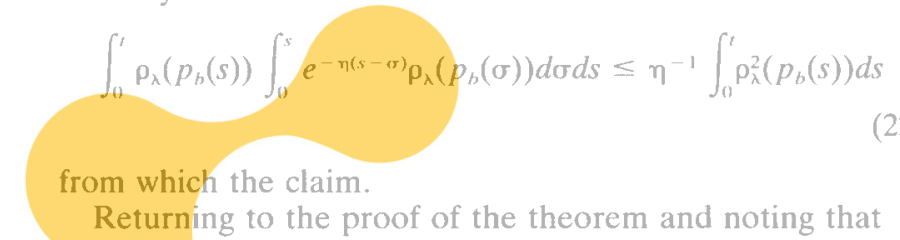

Returning to the proof of the theorem and noting that $\rho_{\lambda}\left(p_{b}(t)\right)+\rho_{\lambda}^{2}\left(p_{b}(t)\right) \leq\left(1+\lambda^{-1}\right) p_{\lambda}\left(p_{b}(t)\right)\left|p_{b}(t)\right|$
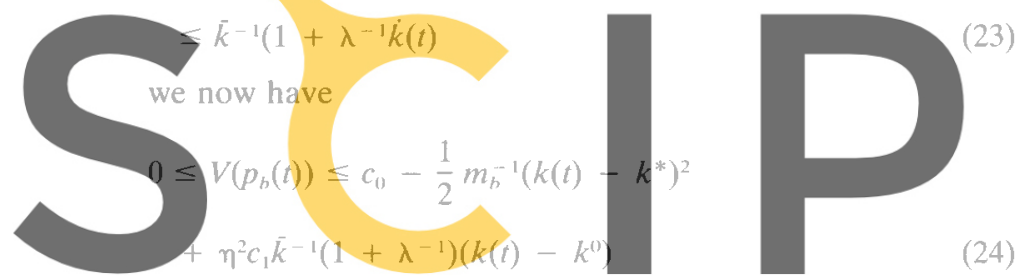

for all $t \in[0, \omega)$. Therefore, we see that the monotone inRegister creasing function $k\left(b^{\prime}\right)$ is boynded. This in turn, implies
diately follows that $d_{b}(\cdot)$ is bounded. By assumption 1, we see that $\{0\}$ is an asymptotically stable equilibrium of the unforced subsystem

$$
\mathbf{M D}+\mathbf{C D}+\mathbf{K D}=0
$$

By the boundedness of $d_{b}(\cdot)$ and $p_{b}(\cdot)$, it follows from the forced equation

$$
\mathbf{M} \ddot{\mathbf{D}}+\mathbf{C} \dot{\mathbf{D}}+\mathbf{K D}=\mathbf{C} \mathbf{J}\left[p_{b}-\eta d_{b}\right]+\mathbf{K} \mathbf{J} d_{b}
$$

that $\mathbf{D}(\cdot)$ and $\dot{\mathbf{D}}(\cdot)$ are bounded. We have now shown that the solution $\xi(\cdot)$ is bounded and so $\omega=\infty$. Assertion (2) of the theorem is now a consequence of the boundedness and monotonicity of $k(\cdot)$.

To prove assertion (3), we argue as follows. Observe that

$$
\begin{aligned}
& \rho_{\lambda}\left(p_{b}(t)\right)\left|d_{b}(t)\right| \leq \rho_{\lambda}\left(p_{b}(t)\right) \lambda^{-1}\left|p_{b}(t) \| d_{b}(t)\right| \\
& \quad \leq(\bar{k} \lambda)^{-1}\left|d_{b}(t)\right| \dot{k}(t)
\end{aligned}
$$

and so, by the boundedness of $d_{b}(\cdot)$, there exists positive scalar $c_{2}$ such that

$$
\eta^{2} \boldsymbol{\rho}_{\lambda}\left(p_{b}(t)\right)\left|d_{b}(t)\right| \leq c_{2} \dot{k}(t)
$$

for almost all $t \geq 0$. Writing $c_{3}:=m_{b}^{-1}\left(k^{*}-k^{0}\right)+c_{2}$, we conclude that

$$
\frac{d}{d t} V\left(p_{b}(t)\right) \leq-\dot{k}(t)+\left(c_{3}+1\right) \dot{k}(t)
$$

for almost all $t \geqslant 0$. Therefore the function $W$ given by

$$
W\left(p_{b}, k\right):=V\left(p_{b}\right)-\left(1+c_{3}\right) k
$$

is such that

$$
\frac{d}{d t} W\left(p_{b}(t), k(t)\right) \leq-\dot{k}(t) \leq-\bar{k}_{p_{\lambda}}\left(p_{h}(t)\right)\left|p_{b}(t)\right|
$$

for almost all $t \geq 0$. The boundedness of the solution $\xi(\cdot)$ ensures that it has a nonempty $\omega$-limit set $\Omega$. Since the solution approaches its $\omega$-limit set, we prove that

$$
\rho_{\lambda}\left(p_{b}(t)\right) \rightarrow 0 \text { as } t \rightarrow \infty
$$

by showing that $\rho_{\lambda}\left(\tilde{p}_{b}\right)=0$ for all $\tilde{\xi}=\left(\tilde{\mathbf{D}}, \tilde{\mathbf{V}}, \tilde{d}_{b}, \tilde{k}\right) \in \Omega$. Suppose otherwise. Then there exists $\tilde{\xi}=\left(\tilde{\mathbf{D}}, \tilde{\mathbf{v}}, \tilde{d}_{b}, \tilde{p}_{b}, \tilde{k}\right)$ $\in \Omega$ and $\varepsilon>0$, such that $\rho_{\lambda}\left(\tilde{p}_{b}\right)\left|\tilde{p}_{b}\right|>2 \varepsilon$. By continuity, there exists $\delta>0$ such that

$$
\left|p_{b}-\tilde{p}_{h}\right|<\hat{\delta} \Rightarrow \bar{k}_{p_{h}}\left(p_{h}\right)\left|p_{h}\right|>\varepsilon
$$

Since $\tilde{\xi}$ is an $\omega$-limit point, there exists a sequence $\left(t_{i}\right)$ with $t_{i} \rightarrow \infty$ and

$$
\xi\left(t_{i}\right)=\left(\mathbf{D}\left(t_{j}\right), \dot{\mathbf{D}}\left(t_{j}\right), d_{h}\left(t_{j}\right), p_{b}\left(t_{i}\right), k\left(t_{j}\right)\right) \rightarrow \tilde{\xi}
$$

as $j \rightarrow \infty$. Using assumptions 2 and 3 , it is readily verified that $\bar{\delta}>0$ and $R>0$ exist such that

$$
\|\xi-\tilde{\xi}\|<\tilde{\delta} \Rightarrow\left\|F_{\wedge}(t, \xi)\right\|<R
$$

We may assume $\tilde{\delta}<\tilde{\delta}$. By the continuity of $W$

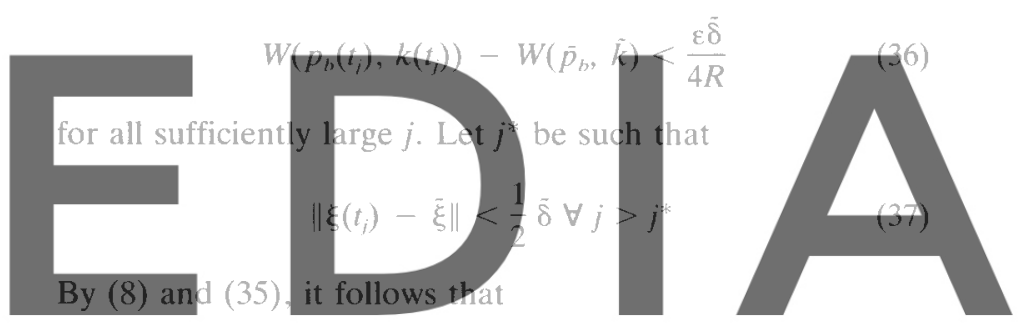

$$
\begin{aligned}
& \text { download the version without the waterm } \\
& \text { which holds for all } j>j^{*} \text {. Therefore, using }(31) \text {, we have for } \\
& \text { all } j>j^{*} \\
& \qquad W\left(p_{b}\left(t_{j}\right), k\left(t_{j}\right)\right)-W\left(\tilde{p}_{b}, \bar{k}\right)>\int_{t_{j}}^{t_{j}+(\bar{\delta} / 3 R)} \bar{k} \rho_{\lambda}\left(p_{b}(t)\right)\left|p_{b}(t)\right| d t \geq \frac{\varepsilon \tilde{\delta}}{3 R}
\end{aligned}
$$

which contradicts (36). Therefore, $\rho_{\gamma}\left(p_{b}(t)\right) \rightarrow 0$ as $t \rightarrow \infty$. Since $\dot{d}_{b}(t)=-\eta d_{b}(t)+p_{b}(t)$, we also have $\rho_{\lambda \eta}{ }_{1}\left(d_{b}(t)\right) \rightarrow$ 0 as $t \rightarrow \infty$. This establishes assertion 3 .

Finally, the asymptotic stability of the unforced system (25), with (26) and assertion 3 , yields assertion 5 .

\section{APPENDIX II. REFERENCES}

Coddington, E. A., and Levinson, N. (1953). Theory of ordinary differential equation. R. E. Krieger Publ., Malabar, Fla.

Feng, M. Q., Shinozuka, M., and Fujii, S. (1993). "Friction-controllable sliding isolated system." J. Engrg. Mech., ASCE, 119(9), 1845-1864. Inaudi, J., and Kelly, J. M. (1990). "Active isolation." Proc., U.S. Nat. Workshop on Struct. Control Res., Univ. of Southern California, Los Angeles, Calif. 125-130.

Inaudi, J., and Kelly, J. M. (1991). "A simple active isolation scheme." 8th VPI and SU Symp. on Dynamics and Control of Large Struct. Virginia Polytechnic Inst., Blacksburg, Va., 219-231.

Inaudi, J., López Almansa, F., Kelly, J. M., and Rodellar, J. (1992). "Predictive control of base isolated structures." Earthquake Engrg. and Struct. Dynamics, 21(6), 471-482.

Kelly, J. M. (1986). "Aseismic base isolation: review and bibliography." Soil Dynamics and Earthquake Engrg., 5(3), 202-216. 
Kelly, J. M., Leitmann, G., and Soldatos, A. (1987). "Robust control of base-isolated structures under earthquake excitation." J. Optimization Theory and Application, Vol. 53, 159-181.

Nagarajaiah, S., Reinhorn, A. M., and Constantinou, M. C. (1989). "Nonlinear dynamic analysis of three-dimensional base isolated structures (3D-Basis)." Tech. Rep. NCEER-89-0019, Nat. Ctr. for Earthquake Engrg. Res., State Univ. of New York at Buffalo, N.Y.

Nagarajaiah, S., Reinhorn, A. M., and Constantinou, M. C. (1991) "Nonlinear dynamic analysis of three-dimensional base isolated structures: part II." Tech. Rep. NCEER-91-0005, Nat. Ctr. for Earthquake Engrg. Res., State Univ. of New York at Buffalo, N.Y.

Nagarajaiah, S., Riley, M., Reinhorn, A. M., and Shinozuka, M. (1992). "Hybrid control of sliding isolated bridges." Proc, 1992 Pressure Vessels and Piping Conf., ASME/PVP-237, Am. Soc. of Mech. Engrs. (ASME), New York, N.Y., Vol. 2, 83-89.

Riley, M., Nagarajaiah, S., and Reinhorn, A. M. (1992). "Hybrid control of absolute motion in aseismically isolated bridges." Proc., 3rd NSF Workshop on Bridge Engrg. Res., Univ. of California, San Diego, Calif., 239-242.

Rodellar, J., and Ryan, E. P. (1993). "Adaptive control of uncertain coupled mechanical systems." Preprints 12th IFAC World Congr., Int. Federation of Automatic Control (IFAC), Sydney, Australia, Vol. 8, $187-190$

Skinner, R. I., Robinson, W. H., and Mcverry, G. H. (1993). An in troduction to seismic isolation. John Wiley \& Sons, Chichester, England.

Soong. T. T. (1990). Active structural control. Longman Scientific \& Technical, Burnt Mill, Harlow, England.

Su, L.. Ahmadi, G. and Tadjbakhsh. I. G. (1989). "A comparative study of performances of various base isolation systems, Part I: Shear beam structures." Earthquake Engrg. and Struct. Dynamics, 18(1),

$11-32$

Yang, J. N., Danielians, A., and Liu, S. C. (1992). "Aseismic hybrid
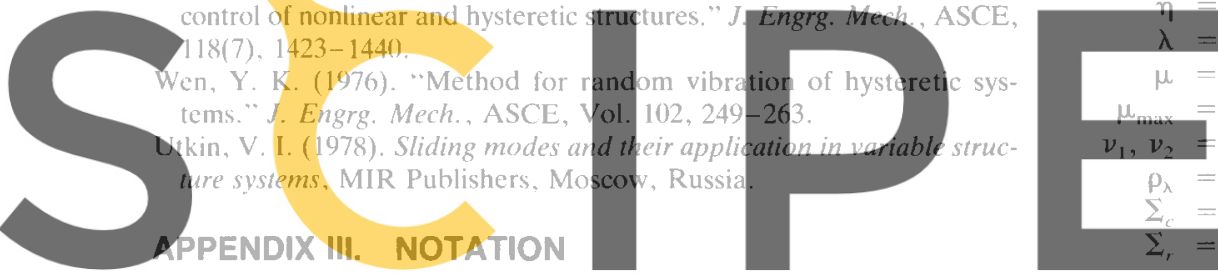

The following symbols are used in this paper. $c_{b}=$ damping of base;

$\mathbf{D}=$ absolute displacement vector of structure

$d=$ ground displacement;

$d_{b}=$ absolute displacement of base;

$f=$ nonlinear force in isolator;

$f_{1}=$ frictional force in isolator;

$f_{2}=$ hysteretic force in isolator;

$f^{y}=$ yielding force;

$\boldsymbol{J}=$ unit vector;

$\mathbf{K}=$ stiffness matrix of structure;

$k=$ time-varying gain in control law;

$k_{b}=$ stiffness of base;

$k_{\underline{g}}=$ initial value of gain;

$\bar{k}=$ scale factor in gain equation $(6 b)$

$\mathbf{M}=$ mass matrix of structure;

$m=$ parameter of hysteretical model (12);

$m_{b}=$ mass of base;

$p_{h}=$ linear combination of base displacement and velocity in control law;

$Q=$ force normal to the friction surface in $(10)$

$s,=$ function in $(7 a)$ :

$=$ time:

$u=$ active control force;

= ground velocity:

= base displacement relative to the ground;

= auxiliary variable in hysteretic model (12);

unknown scalar in (3);

$=$ coefficient in frictional model $(10)$;

= function in control law;

$=$ bounding function in (3);

$=$ bound for the excitation in $(2)$;
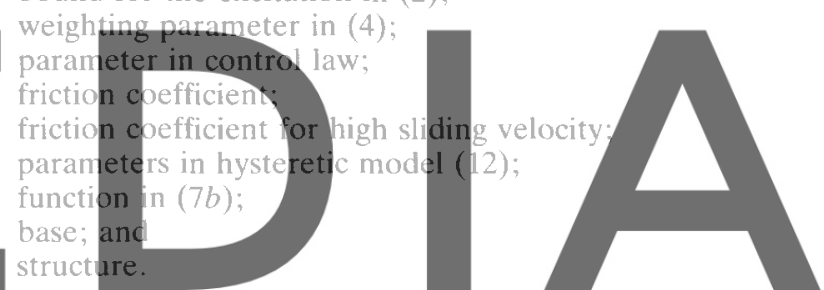

$\mathrm{C}=$ damping matrix of structure; 